\title{
Observação compreensivo-crítica das experiências de movimento corporal das crianças na educação infantil
}

\author{
Nelson Figueiredo de Andrade Filho*
}

\begin{abstract}
Resumo: Esta é uma investigação sobre como ocorrem às experiências de movimento corporal das crianças em um Centro de Educação Infantil. Constitui uma pesquisa etnográfica que utiliza a observação compreensivo-crítica como abordagem teórico-metodológica. A observação permitiu perceber que as experiências de movimento corporal das crianças tendem a ser interditadas pela cultura de escolarização; que as crianças não têm direito a movimentar a si e ao seu mundo como precisam e têm interesse de fazê-lo; que quando a criança move a si e ao seu mundo provoca forte conflito entre sua perspectiva ética estética e a ordem cultural escolar.
\end{abstract}

Palavras-chave: Educação Infantil. Criança. Experiências de Movimento Corporal. Observação.

\section{INTRODUÇÃo}

A questão que orientou a construção da abordagem temática dessa investigação foi: como ocorrem as experiências de movimento corporal das crianças no dia a dia de um Centro Municipal de Educação Infantil (CMEI), do município de Vitória (ES)? A abordagem teórico-metodológica constitui-se de uma observação compreensivo-crítica.

\footnotetext{
"Professor adjunto do Departamento de Ginástica (DG) do Centro de Educação Física e Desportos (CEFD) da Universidade Federal do Espírito Santo, Vitória, ES, BRASIL. E-mail: nelsonfaf@hotmail.com
} 
Propusemo-nos a estudar as experiências de movimento corporal das crianças, objetivando contribuir para que a Educação Física constitua elementos teóricos e metodológicos específicos, capazes de orientar a atuação e a formação do professor que estiver envolvido no processo de educação com cuidado das crianças pequenas, em contextos escolares infantis.

Em meio a múltiplas análises que o estudo permitiu desenvolver, priorizamos preocupações básicas acerca da experiências de movimento corporal das crianças na educação infantil, com intuito de compreender criticamente sobre as lógicas de ação e as prescrições "curriculares" didático-pedagógicas que se apõem cotidianamente ao direito que as crianças têm de viver suas experiências de movimento corporal, entendidas aqui como parte do seu oficio de criança (SIROTA, 2001).

\section{AABORDAGEM METODOLÓGICA DESTA INVESTIGAÇÃO}

Entre as referências teóricas sobre etnografia que encontramos, deparamo-nos com estudos de caráter estritamente metodológicos, voltados às Ciências Sociais, à questões do campo da educação escolar e aos estudos das crianças e da infância.

Sem pretender ignorar ou desconsiderar as orientações contidas nos estudos dos diferentes autores, decidimos adotar a perspectiva teórico-metodológica interpretativo-crítica, proposta por Sarmento (2000, 2003a, 2003b), bem como as perspectivas participativas apresentadas por Sarmento, Thomás, Fernandes (2004), como referência para pensar a abordagem metodológica do objeto desta investigação também em sua dimensão empírica.

Conforme Sarmento (2000a, 2003), as premissas teóricas orientadoras das investidas investigativas, na perspectiva interpretativo-crítica são: 
a) Pressuposto epistemológico da singularidade: por esse eixo vale compreender/interpretar criticamente as singularidades, as diferenças, as infinitas variações dentro de um campo de possibilidades, a emergência do inesperado, o fluido, o ambíguo;

b) Pressuposto epistemológico das dimensões intersubjetivas da ação: por esse eixo vale compreender/interpretar criticamente os sistemas interpretativos gerados e geradores da ação dos atores sociais, envolvidos na relação social que ambienta o problema em estudo;

c) Pressuposto epistemológico da natureza eminentemente linguística da investigação interpretativa da ação: por esse eixo, vale compreender/interpretar criticamente as interações comunicativas verbais. Mesmo e especialmente aquelas interações difusas, incompletas, distorcidas dos significados atribuídos às ações pelos atores, durante o funcionamento e a dinâmica organizacional ocorrentes, particularmente no interior das escolas;

d) Pressuposto epistemológico da reflexividade epistemológica: por esse eixo, vale compreender/interpretar criticamente o grau de vigilância ou de auto-análise que o investigador estabelece com/contra suas próprias convicções, observações e interpretações do objeto em estudo.

Argumentando ainda em defesa da perspectiva em questão, referindo-se a Michel Maffesoli, Sarmento (2003a, p. 153-154) acrescenta que esse sociólogo orienta que, na investigação do cotidiano, o investigador deve estar atento aos "pequenos nadas", às "criações em estilo menor que constituem a vida de todos os dias".

Por conseguinte, indica que o investigador precisa considerar que o método deve ser entendido como um roteiro de coleta de informações, em situação social real, e não como a garantia da apreensão da realidade em si e, ainda, que pela via da observação crítica, podem-se conhecer, efetivamente, possibilidades e realizações da realidade cultural da escola. 


\subsection{O CAMPO INVESTIGADO}

A instituição escolhida para sediar o trabalho de campo desta investigação foi o Centro Municipal de Educação Infantil Zélia Viana de Aguiar (CMEI ZVA). Com o qual mantivemos, entre os anos de 2002/1 e 2006/1, permanentes relações de aproximação e diálogo, durante a ação formativa de professores de Educação Física, para atuar na Educação Infantil, desde o início do processo de formação docente, desenvolvido para este fim, a partir do CEFD/UFES.

Visando orientar melhor nosso olhar etnográfico, entre junho e dezembro de 2007, observamos detidamente, situados dentro das salas, o trabalho pedagógico das professoras regentes com todos os 23 grupos de crianças do CMEI ZVA. Do Berçário 1 ao Pré-Escolar, nos períodos matutino e vespertino. Essa intensa observação gerou um quantitativo de 370 páginas de registros escritos em três volumes do caderno de campo. Gerou também 880 fotos dos ambientes do CMEI, de pessoas, reuniões e atividades de sala, em cerca de 250 horas de presença na instituição. Na instituição, observamos reuniões, reconhecemos ambientes, materiais, etc., conversamos com a diretora, com as pedagogas, com os diferentes funcionários, com as professoras e as crianças. Acompanhamos a organização do trabalho pedagógico de rotina, acompanhamos as atividades do grupo em que estávamos e, ainda, registramos algumas horas de conversas e reuniões, gravando-as em áudio. No que se refere à observação direta do trabalho das professoras com os grupos de crianças em sala ou no pátio, registramos aproximadamente 115 horas de presença nos grupos.

A observação in loco permitiu-nos registrar no caderno de campo os acontecimentos pedagógicos e as experiências de movimento corporal das crianças. Além de narrar, de modo compreensivo-crítico a cronologia e a duração da ação, descrevemos o espaço em que a ação ocorreu, indicamos os participantes, os modos de organização e desenvolvimento da atividade - individual ou grupal -, se a atividade foi de iniciativa do professor ou da criança. 


\section{COMO OCORREM AS EXPERIÊNCIAS DE MOVIMENTO CORPORAL DAS CRIANÇAS NO CONTEXTO DA EDUCAÇÃO INFANTIL?}

Voltamos a focar os objetivos imediatos do estudo e dedicamosnos a discutir consignando temáticas que entendemos como suficentes para contemplar nossas preocupações básicas com a questão das experiências de movimento corporal das crianças na escola infantil, conforme enunciamos na introdução.

\subsection{Dados sobre os SuJeitos do CMEI}

O CMEI ZVA possui 23 turmas, cada uma delas com 20 crianças em média. Essas turmas são organizadas por grupo de idades que variam de seis meses a seis anos e seis meses. Organizados da seguinte forma:

(I) Berçários - crianças com idades variando entre 6 meses e 1 ano e 6 meses, sob a responsabilidade de 4 funcionárias, sendo 2 professoras e 2 auxiliares por turma, em 3 turmas (A, B matutinas, $C$ vespertina).

(II) Berçários - crianças com idades variando entre 1 ano e 7 meses e 2 anos e 6 meses, sob a responsabilidade de 3 funcionárias, sendo 1 professora e 2 auxiliares por turma, em 4 turmas (A, B matutinas, $\mathrm{C}, \mathrm{D}$ vespertinas).

(III) Maternais - crianças com idades variando entre 2 anos e 7 meses e 3 anos e 6 meses, sob a responsabilidade de 2 funcionárias, 1 professora e 1 estagiária por turma, em 4 turmas (A, B matutinas, $\mathrm{C}, \mathrm{D}$ vespertinas).

(IV) Jardim I - crianças com idades variando entre 3 anos e 7 meses e 4 anos e 6 meses, sob a responsabilidade de 1 professora por turma, em 4 turmas (A, B matutinas, C, D vespertinas).

(V) Jardim II - crianças com idades variando entre 4 anos e 7 meses e 5 anos e 6 meses, sob a responsabilidade de 1 professora por turma, em 4 turmas, (A, B matutinas, C, D vespertinas). 
(VI) Pré-Escolares - crianças com idades variando entre 5 anos e 7 meses e 6 anos e 6 meses, sob a responsabilidade de 1 professora por turma, em 3 turmas (A, B matutinas, $\mathrm{C}$ vespertina).

3.2 A INTERDIÇÃO DO MOVIMENTO CORPORAL DAS CRIANÇAS NA DINÂMICA ESCOLAR: UMA ANÁLISE COMPREENSIVO-CRÍTICA

Nesse artigo delimitamos, significativamente, a discussão às situações de interdição das experiências de movimento corporal das crianças observadas ao longo do trabalho de campo. Por hora, priorizamos destacar situações, nas quais as crianças emergiram como atores decisivos no acontecimento pedagógico vivido e observado.

Observando os grupos do CMEI ZVA pudemos compreender que frequentemente as crianças gostam das atividades que lhes são prescritas. Entretanto, interferem decisivamente no modo como as atividades são realizadas. $\mathrm{Na}$ ação as crianças sugerem e até impõem outros conteúdos e outros modos de experienciá-los, diferentes daqueles que normalmente a professora prescreve.

Vimos que, de fato, as crianças gostam de escolher as atividades que realizam, bem como de indicar o modo de realizá-las. As evidências que colhemos e que nos parecem bastante suficientes para sustentar essa opinião indicam que, no dia a dia da educação infantil observada de dentro, quando há atividades propostas pelas professoras e auxiliares as crianças envolvem-se nessas atividades e procuram desenvolvê-las, em parte como as professoras orientam, em parte como lhes parece possível ou interessante fazê-lo. Entretanto, quando, por um minuto, tais atividades cessam, tardam, falham ou faltam e as crianças o notam e sentem-se à vontade e em condições de agir por conta própria, elas rapidamente dispersam, desinteressando-se pelo agir prescrito e interessando-se pelo agir experiencial. Divertem-se ou abrem disputas renhidas pela posse de um objeto ou pelo controle de uma situação; individualmente e/ou em pequenos grupos. 
Nas salas, observando os diversos grupos, vimos crianças subirem no túnel de plástico, escorregarem dali e, imediatamennte, subirem no gradio das janelas; subirem no urso baú, para em seguida dali saltar e correr. Vimos que, quando as crianças ficavam desocupadas, logo corriam para brincar ou brigar dentro do túnel de plástico, para disputar brinquedos, chinelos, medir forças via empurraempurra ou provocação mútua. Em determinado momento, vimos que enquanto uma criança dormia, outra batia numa terceira, outra esbarrava com a cabeça na parede e uma quinta também batia em outra criança dentro da casinha de brinquedo lá existente. Vimos crianças brincar de lutas, capoeira, em frente ao espelho. Vimos uma menina, M. A., tentar jogar no ventilador uma tampa plástica de uma panelinha da cozinha de brinquedo, e, não conseguindo acertar o alvo, voltar para a mesa onde as demais crianças começavam a cercar a professora de Artes Visuais, que acabava de adentrar o recinto.

Em outro ambiente do CMEI, no pátio, observamos que o tempo e o espaço disponíveis pareciam apropriados para as crianças. Se em sala havia a presença das professoras e das auxiliares, coordenando os trabalhos, de forma e modo a controlar as pretenções das ações infantis; no pátio, diferentemente, combinou-se o tempo e o espaço amplos, com as ausências das professoras, por estarem em horários de lanche, com a vigilância displicente das auxiliares e assistentes de serviços gerais, encarregadas de acompanhar as crianças, à distância, próprio da "hora do recreio", para gerar uma "verdadeira" hora da manifestação corporal consentida. Um tempo certo em um lugar próprio para as crianças se manifestarem corporalmente, livres de qualquer diretividade típica da interveção pedagógica regular, indo e vindo, sem que ninguém lhes orientasse ação educativa prescrita alguma.

Se ao compreender criticamente que quando as crianças observadas no CMEI ZVA, inúmeras vezes moveram a si sem o consentimento da professora, quando agiram e reagiram afirmativa ou negativamente às suas orientações didático-pedagógicas, quando convidaram ou rejeitaram outra criança, a professora, o investigador 
no momento em que pretendiam brincar desta ou daquela brincadeira, ao seu modo, não constituiu absurdo, invencionisse, farsa; se pudermos considerar que tais acontecimentos são indícios plausíveis de que as crianças são competentes para estabelecerem as ações, os processos, à ordem social que lhes satisfaz e interessa, um aspecto resta para, por hora, fechar essa discussão. Trata-se de aceitar a perspectiva compreensivo-crítica até agora esboçada, por exigência do objeto sob investigação, como suficiente para reconhecer as experiências de movimento corporal das crianças como possibilidade concreta de ela realizar ativamente o seu ponto de vista no contexto da Educação Infantil, e, possivelmente, em meio a outros contextos, condições e "arranjos" sociais em que se encontra.

Podemos assim, a partir do modo como procedemos a discussão teórico-metodológica e a investigação etnográfica compreensivocrítica, considerar que as experiências de movimento corporal das crianças são uma fonte instituidora de um modo válido de reconhecer a ela como sujeito de ação social, a partir de seu ponto de vista. Sim, porque no que se refere à dimensão empírica dessa questão, observamos que normalmente as crianças envolveram-se inteiramente, intensamente e intencionalmente, movendo corporalmente a si, para viabilizar os acontecimentos, dentro das mais diferentes atividades programadas pelas professoras e pela escola, assim como também realizaram intencionalmente experiências de movimento corporal quando faltaram atividades previamente programadas. Em qualquer desses dois cenários, agindo deram os sentidos que lhes interessavam ao acontecimento, a partir da ação, não por obra primeira e exclusiva de qualquer outra forma predefinida de raciocínio expressivo, discursivo, etc.

Aliás, não fossem essas evidências empíricas, poderíamos também argumentar, com base em elaborações teóricas como as que Ferreira (2004) desenvolveu, realizando suas investigações em um Jardim de Infância em contexto português, que só não vai compreender outras possibilidades heurísticas relativas ao conceito de ação social quem pensa a ação social na perspectiva weberiana "[...] concepção tradicional que apresenta o sentido como a priori da 
acção e esta como sinônimo da acção racional, ancorando numa razão que, por sua vez, se faz coincidir com consciência e reflexividade, e torna manifesta por via do discurso e da explicitação das intenções que lhe presidem." (FERREIRA, 2004, p. 105, grifos da autora), ou seja, quem pensa a ação social e, assim também pensaria as experiências de movimento corporal da criança, por um prisma adulto "puro".

Diferentemente dessa perspectiva, pensamos as experiências de movimento corporal das crianças observadas no cotidiano da escola infantil como um tipo de ação social produzida pela criança, conforme seu interesse e seu ponto de vista, em que a racionalização do ato ocorre depois da ação ou no fluxo da ação, enfatizando sua natureza tácita. Feição outra que, conforme argumenta a referida autora, não compromete o papel da reflexividade humana nos processos de interação social.

Trata-se, portanto, de reconhecer pela observação e pela argumentação teórica acadêmica que as experiências de movimento corporal das crianças constituem um tipo de ação social fundante de uma consciência prática e de uma consciência da prática, "[...] que é um conhecimento incorporado naquilo que os actores "sabem fazer" e sabem como continuar" (GIDDENS, 2000. apud FERREIRA, 2004, p. 109). Um tipo de ação social refinada, seletiva, interferente e, muitas vezes, determinante no processo de interação social que, "ao fim e ao cabo", pela negociação ou pelo conflito, claramente evidencia o ponto de vista da criança, tanto mais quanto menos ela se expresse como os adultos.

Podemos, ainda, reconhecer na prática o direito de a criança ter direito de mover a si na educação infantil. Sim, porque a observação cotidiana da escola infantil levou-nos a rapidamente perceber que as crianças têm mais expectativas de direitos que direitos de fato. A observação levou-nos a perceber que no discurso corrente, notadamente no discurso adulto promovido pelas pedagogas, professoras e auxiliares é fácil ouvir a pronúncia dos direitos das crianças como um modo de falar de atrizes que não podem supor desconhecer a lei (por exemplo: a Convenção Internacional sobre 
os Direitos das Crianças, promulgada pela Organização das Nações Unidas, em 1989), mas que, no dia a dia, agem politicamente ancoradas no discurso acadêmico resultante do modelo desenvolvimentista, reduzindo as experiências de movimento corporal das crianças como ação social à linguagem.

Desmistificando, entretanto, a encenação, Fernandes (2009) considera que entre um discurso socialmente presente que defende a criança como ator social dependente e outro que advoga pelo direito de uma criança emancipada, grassa ambivalência suficiente para interditar ou postergar o reconhecimento público social de uma possível criança participativa. Conforme a autora, a mais forte ambivalência desse debate emerge quando se discute a natureza dos grandes conjuntos de direitos (provisão, proteção, participação) legalmente propostos para regular a vida das crianças em sociedade.

Observando as crianças no CMEI, compreendemos que um outro nome forte para essa "ambiguidade" é "cuidado", modo responsável com o qual as pessoas adultas nomeiam o "empate" das ações das crianças e, efetivamente, comandam e determinam que as crianças sejam sistematicamente tratadas pelo coletivo institucional. Como dissemos antes, em nome da educação com cuidado, frequentemente professoras e auxiliares não permitem que as crianças movam corporalmente a si na educação infantil, em razão dos riscos inerentes às experiências de movimento corporal que comumente praticam. Ocorre também que, entretanto, quanto menos a criança ativa é de "diálogo", menos pauta sua ação pela ideia de cuidado prescrito. Cuidado prévio que se for plenamente compreendido pela criança implica na exigência de não mover a si, antes que essa ação seja pedagogicamente orientada ou autorizada, conforme certo molde.

Ante o quadro ideal de direitos consentidos, vimos crianças agirem e, com a sua ação, gerarem evidências ou indícios desestabilizadores das perspectivas pedagógicas institucionais históricas. Por adquirir essa percepção é que nos limitamos a pensar e dizer que, em nossa perspectiva, uma análise compreensiva crítica é, antes de tudo, um modo de olhar para as experiências cotidianas 
de movimento corporal que emergem das ações e reações das crianças encontradas em um determinado contexto educacional infantil, reconhecendo que as experiências, ações, reações, interações das crianças constituem indícios suficientes de suas necessidades, interesses, vontades, pontos de vistas. Por consequência, reconhecer que esses indícios colocam em causa todo o nosso conhecimento e, também, todo o nosso próprio ponto de vista sobre o que sabemos das crianças e das suas experiências em sociedade. Nesse sentido, compreendemos criticamente que as ações e reações das crianças em suas experiências de movimento corporal são indícios do seu poder pessoal e social, da sua capacidade de provocar "vertigem" em nossa mentalidade e de abalar nossas certezas.

Vertigem é uma palavra que bem significa que passamos a pisar em falso, não no sentido de uma qualquer falsidade, porém na acepção de pisar em algo que nos faz afundar, num fundo quiçá abissal. São nossos próprios fundamentos quem sofrem esse abalo. A vertigem, por assim dizer, faz tremer nossas próprias estruturas, interrogando-nos sobre nosso modo de pensar e de ser. Ela sacode de uma forma firme, nossas convicções. (ROSENFIELD, 2001, p. 197).

Essa decifração da dificuldade adulta de ponderar os fazeres das crianças nos pareceu bastante plausível quando, ao observarmos as ações relacionadas às experiências de movimento corporal das crianças no CMEI, ouvimos professoras enunciarem "Esse aí só Deus!", ao comentar o comportamento "indomável" desta ou daquela criança ativa. Ante tal evidência empírica da dificuldade adulta da professora para pedagogicamente transigir com as ações experienciais da criança é que nos pareceu bastante razoável refletir que a docente, naquele momento, sofria, passava, por uma experiência de vertigem, conforme a perplexa sentença, anteriormente exposta, deixa notar.

Uma experiência vertiginosa em forma de ação experiencial infantil que, em nosso modo de enxergar, exigia da professora que enxergasse a si e ao outro que agia no contexto, pois estava diante 
de um tipo de ação ou reação da parte das crianças, capaz de baralhar ideias, palavras, linguagens da profissional "escalada" para gerir o processo de educar com cuidado lá estabelecido. Experiência vertiginosa sim, tanto mais, quanto mais acadêmicas e pedagógicas de certas cepas eram as ideias, palavras, ações da docente; tanto mais quanto mais sua racionalidade, visão de mundo, de sociedade e de "homem" no mundo, de educação do homem no mundo vigorava. Enfim, tanto mais quanto mais demonstrava ter, por exemplo, uma possante visão dos acontecimentos que presenciava calcada nos postulados clássicos da Psicologia do Desenvolvimento Humano e em certa perspectiva sociológica da ação.

Ponderando informações vindas da realidade vivida com ou contra postulados filosóficos, como esses explorados por Rosenfield (2001), podemos pensar que as crianças não são seres civilizados. Apesar de nascerem e receberem influências primeiras dos códigos civilizados da sociedade que lhes ofertamos quando irrompem no mundo. De fato, é possível perceber nas expressões dos adultos que as crianças vivem a perturbar, a atrapalhar, a determinar ritmos e obrigações que os adultos repudiam a todo o momento. $\mathrm{O}$ comportamento civilizado adulto ante o comportamento incivilizado das crianças é que nos fez pensar que as crianças principiam por serem seres ontologicamente violentos às nossas boas intenções em favor dos direitos e da proteção do melhor interesse delas.

Ao propor antes que as ações experienciais de movimento corporal das crianças na Educação Infantil são uma sua chave de socialização, uma parte do seu ofício de criança, agora, radicalizando, sugerimos que, no contexto do processo de escolarização que se lhes imputam o sistema educacional e os adultos que o operam, tais experiências de movimento corporal, em princípio, configuram ações ontologicamente violentas. Ações concorrentes indóceis às nossas boas intenções para com as necessidades e interesses pessoais e sociais das crianças. Nesse sentido, chamando intencionalmente o debate para o campo do direito a ter direitos ou, valendo-nos das 
proposições de Rosenfield (2001), consideramos este acontecimento existencial, pedagógico, social e cultural produzido pelas crianças como um momento fundador de novos direitos.

Por esse prisma, as experiências de movimento corporal das crianças que observamos no dia a dia de um CMEI do sistema público de ensino de Vitória, ES, constituem um modo legítimo de as crianças instituírem a si como sujeitos de ações e reações que estabelecem princípios e sentidos plausíveis, relativos aos poderes, direitos, conhecimentos e culturas próprias das crianças. Modo legítimo de reivindicar a transformação da ordem instituída, fazendo com que o sucesso da escolarização até aqui praticada não se dê pela punição das possibilidades de socialização necessárias e interessantes ao sujeito que dá sentido à existência da própria ordem instituída, assim como, algumas vezes, se dê ao arrepio dos princípios e processos que justificam a existência institucional.

Trocando em miúdos, a observação das experiências de movimento corporal das crianças no dia a dia de uma instituição educacional infantil pública de Vitória, por entre o trabalho pedagógico que dentro da instituição laboriosamente desenvolve-se, indica que em suas ações e reações à ordem e ao trabalho escolar proposto, as crianças estão cada vez menos dispostas a adaptar-se àquela estrutura ordenada, exigindo que o sistema e a instituição educativa transformem-se, em virtude da manutenção da sua própria necessidade social e política, para se adaptar as novas demandas legítimas e legais, ao novo estatuto social das crianças.

$\mathrm{Na}$ perspectiva compreensivo-crítica, induzida por essa investigação, trata-se de propor à Universidade e aos demais setores que regem a vida pública social brasileira que reconheçam que as crianças exigem na prática o cumprimento dos seus direitos, o reconhecimento político das suas competências relativas e a ocupação dos lugares sociais que lhe dizem respeito, como condição básica da efetiva experienciação da sua cidadania infantil, dentro do estado e da sociedade democrática moderna. 
Pela perspectiva compreensivo-crítica aqui exercitada podemos, por fim, pensar que as experiências de movimento corporal das crianças configuram, sim, um modo de produção de subjetividade objetivada - conhecimento, socialização e cultura de pares - próprio da criança a partir do trabalho educativo que se realiza na instituição infantil cotidianamente. Pensar também que configura um modo capaz de reorientar a ação pedagógica docente, a organização e o funcionamento da instituição e do sistema educativo investigado, bem como um modo substantivo para contribuir com a estruturação de elementos teóricos e metodológicos específicos da Educação Física para a Educação Infantil, capazes de orientar a atuação e a formação consistente daquele seu professor que desejar efetivamente se envolver no processo de educação com cuidado das crianças pequenas em contextos educativos infantis, conforme almejamos desde o início deste estudo.

\section{Remates finAs}

A observação em contexto e análise compreensivo-crítica nos permitiu compreender que as experiências de movimento corporal das crianças tendem a ser sistematicamente interditadas pela cultura institucional; que as crianças na educação infantil não têm direito a movimentar a si e ao seu mundo como precisam e gostariam de fazê-lo; que o sentido interpretativo desenvolvimentista (histórico) corrente na educação infantil indica que quando a criança move a si e ao seu mundo provoca um forte conflito entre sua perspectiva cultural ética estética e a ordem cultural estética ética institucional.

Ao compreender a tentativa sistemática de interdição das experiências de movimento corporal das crianças, passamos a considerar que essas experiências são uma chave de socialização das crianças; pois os movimentos corporais executados por elas são fundamentais para a configuração de ações inerentes aos jogos e às brincadeiras no momento em que ocorrem; são uma necessidade e um interesse típico e parte significativa do ofício de criança. Esse é um sentido seminal que os conhecimentos adquiridos com a Sociologia da Infância nos permitiram criticamente compreender. 
Se essas necessidades e interesses não forem considerados no dia a dia da educação infantil, expropria-se a chave e comprometese sensivelmente o desenvolvimento, a educação, socialização da criança como sujeito de direitos. Experiências de movimentos corporais vividas pelas crianças são necessárias como fontes de ação e realização, possibilidade efetiva de aquisição de um tipo de conhecimento objetivo, estruturante, regulador e revelador das experiências, das ações, da linguagem, da subjetividade, das representações das dimensões reais e virtuais da vida e das condições efetivas de socialização da criança. 


\section{Comprehensive-critical observation of experiences of the corporal movement of children in infant education}

Abstract: This is an investigation about how the experiences of the corporal movement of children happen in an Infant Education Center. Constitutes an ethnographic research that utilizes comprehensivecritical observation as theoretical-methodological approach. The observation of the children allowed to notice that corporal movement experiences of the children tend to be interdicted by the culture of institutional schooling; that children at school do not have the right to move themselves and in their world the way they need and would like to do; that when children move themselves and their own world, it provokes strong conflict between the ethical esthetical perspective and the school cultural order.

Keywords: Child Rearing. Child. Experiences of the Corporal Movement. Observation.

\section{Observación comprensiva-crítica de experiencias de movimiento corporal de niños en la educación infantil}

Resumen: Esta es una investigación sobre cómo se dan las experiencias de movimiento corporal de niños en un Centro de Educación Infantil. Se trata de una investigación etnográfica, con observación comprensiva-crítica como abordaje teóricometodológico. La observación permitió percibir que las experiencias de movimiento corporal de niños tienden a ser interdichas por la cultura institucional; que los niños no tienen derecho a moverse a sí mismos y a su mundo como necesitan y les gustaría hacerlo; que cuando el niño se mueve a sí y a su mundo provoca fuerte conflicto entre su perspectiva ética estética y el orden cultural escolar.

Palabras clave: Crianza del niño. Niños. Experiencias de Movimiento Corporal. Observación. 


\section{REFERÊNCIAS}

FERNANDES, Natália. Infância, direitos e participação: representações, práticas e poderes. Porto: Afrontamentos; 2009.

FERNANDES, Natália; SARMENTO, Manuel Jacinto; TOMÁS, Catarina. Investigação da infância e crianças como investigadoras: metodologias participativas dos mundos sociais das crianças. In: INTERNACIONAL CONFERENCE ON SOCIAL METHODOLOGY, 6., 2004, Amsterdã. [Anais...]

FERREIRA, Manuela. A gente gosta é de brincar com os outros meninos!: relações sociais entre crianças num jardim de infância. Porto: Edições Afrontamento, 2004.

ROSENFIELD, Denis L. Derrida e a questão do mal. In: ROSENFIELD, Denis L. (Org.). Ética e estética. Rio de Janeiro: Zahar, 2001. p. 197-215.

SARMENTO, Manuel Jacinto. Lógicas de acção nas escolas. Lisboa: Instituto de Inovação Educacional; 2000.

. O estudo de caso etnográfico em educação. In: ZAGO, Nadir; CARVALHO, Marília Pinto de; VILELA, Rita Amélia Teixeira. Itinerários de pesquisa: perspectivas qualitativas em sociologia da educação. Rio de Janeiro: DP\&A; 2003a. p. 137-179.

Quotidianos densos: a pesquisa sociológica dos contextos de acção educativa. In: GARCIA, Regina Leite (Org.). Método métodos contramétodo. São Paulo: Cortez, 2003b. p. 91-109.

SIROTA, Régine. Emergência de uma Sociologia da Infância: evolução do objeto e do olhar. Cadernos de Pesquisa, São Paulo, n. 112, p. 7-31, mar. 2001.

Endereço para correspondência:

Nelson Figueiredo de Andrade Filho

Rua Dr. Moacyr Gonçalves, 297,

Edifício Abaeté, Apto 203 B

Jardim da Penha, Vitória, ES.

CEP: $29060-445$

Recebido em: 16.03.2012

Aprovado em: 17.11.2012

ovimento, Porto Alegre, v. 19, n. 01, p. 55-71, jan/mar de 2013. 